\title{
Basic reading and reading-related language skills in adults with deficient reading comprehension who read a transparent orthography
}

\author{
Irit Bar-Kochva ${ }^{1,2}$ (D) Réka Vágvölgyi ${ }^{3,4}$ (D) Thomas Dresler ${ }^{4,5}$ (D) \\ Benjamin Nagengast ${ }^{4,6}$ (D) Hannes Schröter ${ }^{1}$. Josef Schrader ${ }^{1,4}$. \\ Hans-Christoph Nuerk ${ }^{4,7,8}$ (D)
}

Accepted: 10 March 2021 / Published online: 23 April 2021

(c) The Author(s) 2021

\begin{abstract}
This study set out to examine the basic reading skills (accuracy and fluency in decoding, word and text reading) and some of the reading-related language skills (phonological awareness and rapid-naming) of 54 adults with low reading comprehension, who read the transparent German orthography. Participants were born in Germany and showed a typical non-verbal processing speed. With the exception of reading accuracy, participants were expected to present deficits in all basic reading and reading-related skills. The average performance in measures of decoding and word reading fluency was extremely low. A notable proportion of the sample, however, did not present a deficit in these measures. As expected, the average rate of reading errors was generally low. Nevertheless, text reading accuracy was deficient for one quarter of the sample. Tests addressing the reading-related language skills also indicated an average low performance in phonological awareness, but not in rapid-naming. Here too, a notable variance was observed. These results suggest that deficits in the basic reading skills and in phonological awareness characterise, on average, adults with low reading comprehension. At the same time, significant deficits in reading comprehension in this population do not necessarily imply deficits in the more basic skills of reading as well. In addition, the results indicate that reading accuracy constitutes a source of difficulty for some of these adults, despite the reading of a transparent orthography. The sources for the variance in performance throughout the different reading and reading-related measures remain to be explored.
\end{abstract}

Keywords Low literacy skills · Adults · Basic reading and language skills · Word reading $\cdot$ Decoding

Irit Bar-Kochva

bar-kochva@die-bonn.de; ibarkoch@uni-koeln.de

Extended author information available on the last page of the article 


\section{Introduction}

Low reading ability in adulthood has consistently been reported in large-scale studies worldwide. According to the PIAAC Survey (OECD, 2016) an average of $18.9 \%$ of the working age population (16 to 65 years of age) in the participating countries was found to have insufficient reading ability. According to a more recent assessment of reading and writing skills in Germany, $12.1 \%$ of its population is able to process written sentences but not continuous texts, even if these are brief (LEO 2018, Grotlüschen \& Buddeberg, 2020). Notably, more than half of the adults with low literacy skills in this survey spoke German as their first language.

Adults with low literacy skills experience great difficulties in using printed information in their daily life. For this reason, they have been referred to as "functional illiterates" (UNESCO, 1978). According to Egloff et al. (2011), functional illiteracy is evident when the written language competencies of adults are lower than the expected minimum and lower than those naturally expected in order to meet the demands of society. It has been suggested that this definition can be operationalized by relating it to one's ability to extract meaning from reading and expressing oneself in writing at a reasonable pace. Vágvölgyi et al. (2016) have also put a focus on efficient reading comprehension in their suggested working definition of this group of adults. Difficulty in understanding printed materials such as those related to health, safety, finance, or civic engagement naturally has vast implications on employment prospects, personal development and social engagement (Kutner et al., 2007; OECD, 2016). Importantly, in contrast to illiterates, the group in focus has acquired certain written language skills. Because the term "functional illiteracy" does not communicate its distinction from illiteracy well, it is recommended to avoid the use of this term, and to refer to "adults with low literacy skills" instead (Grotlüschen \& Buddeberg, 2020). This is therefore the term used in the present work.

Low literacy skills in adulthood, which are often evident despite attending the compulsory education system, may be explained by multiple factors (Boltzmann $\&$ Rüsseler, 2013). For instance, social-cultural and/or emotional disadvantages have been suggested to explain inefficient learning in school (Egloff et al., 2011; Eme, 2011; Grosche, 2013). Other factors include deficits in acquiring the foundations of reading, which relate to the ability of efficiently transforming graphemes into their sound units (decoding) and recognizing single words accurately and quickly (Mellard et al., 2010; Nanda et al., 2010). Successful decoding contributes to the development of fast word recognition, which in turn frees up cognitive resources for the complex task of reading comprehension (Ehri, 2005). Additional factors that may explain low literacy skills in adulthood include deficits in certain reading-related oral language skills. Poor performance in measures of phonological processing, syntactic comprehension, morphological knowledge and in some aspects of meta-linguistics has been reported in adolescents and adults with low reading skills (Catts et al., 2006; Eme, 2011; Eme et al., 2014). It may be noted that difficulties in acquiring the basic reading skills, in addition 
to difficulties in some of the mentioned reading-related oral skills, have also been found to characterize children and adults with a reading disability (Snowling \& Melby-Lervåg, 2016). Accordingly, a reading disability, possibly when combined with additional language deficits, has been one explanation suggested for low literacy skills in adulthood (Eme, 2011). Nevertheless, a causal link is difficult to establish, as the role of reading avoidance and a possible lack of proper learning opportunities may also explain the scope of difficulties expressed by this population.

\section{The present study}

The goal of this study was to characterize the basic reading skills and some of the reading-related oral language skills of a sample of adults with low reading comprehension, who read a relatively transparent orthography. More specifically, we were interested in exploring whether these adults present deficits in the building blocks of skilled reading (Ehri, 2005; Lyon et al., 2003), i.e. in accuracy and fluency in decoding and in word reading (when words are presented in isolation and in a text). As far as the reading-related language skills are concerned, we focused on two skills: phonological awareness and rapid-naming (RAN). The relations of these skills with reading development have been widely established (Araújo et al., 2015; Blachman, 2000). Phonological awareness refers to the ability to manipulate and reflect upon the sounds composing the language (McBride-Chang, 1995), whereas RAN refers to the ability to swiftly name visually presented familiar symbols (Wolf \& Bowers, 1999).

When compared to the existing research on children, research on the relations of these skills with reading ability among adults with low literacy skills is scarce. In addition, accumulated data on this population is based mainly on studies of readers of the English orthography. These studies indicate that adults with low literacy skills perform poorly on average across all the skills focused in the present examination (Gottesman et al., 1996, 1997; Mellard \& Fall, 2012; Mellard et al., 2010; Nanda et al., 2010; Thompkins \& Binder, 2003; Winn et al., 2006). However, English represents an extreme case of an opaque orthography, due to its inconsistent spelling and sound relations. It consequently imposes high demands on processes of decoding and word recognition (Share, 2008). Orthographic opacity in combination with other possible factors associated with low literacy skills in adulthood, such as long years of reading avoidance, may in themselves explain low basic reading skills. In contrast, a transparent orthography is expected to facilitate the acquisition of the basic reading skills, such as decoding and accurate word recognition (Share, 2008; Ziegler et al., 2010). Therefore, results obtained in English may not be fully generalized to more transparent orthographies. For this reason, we pursue the question of whether difficulties in the basic reading skills are also evident in adults with low reading comprehension who read a transparent orthography.

It has been suggested that reading-related oral language skills are also influenced by orthographic transparency. Specifically, phoneme awareness has been found to develop earlier in readers of transparent orthographies in comparison to readers of 
opaque orthographies. Orthographic transparency has also been suggested to facilitate phoneme awareness in readers with a reading disability (Goswami et al., 2005; Wimmer, 1993). As far as RAN is concerned, according to a meta-analysis based on data from 137 studies, the RAN-reading relations were stronger in readers of opaque orthographies (Araújo et al., 2015). However, this finding was not supported by a cross-language study in which readers of five orthographies varying in transparency were directly compared (Ziegler et al., 2010).

Only few studies have explored the basic reading and reading-related language skills in adults with low literacy skills, who read orthographies other than English. The study by Eme et al. (2014) reported low performance in word reading, decoding and phonological awareness in adults with low literacy skills who read the French orthography. Studies of adults, who struggle with reading German, confirm low performance in a standardized task addressing word reading fluency (Boltzmann et al., 2017; Grosche \& Grünke, 2011). However, in these studies, low performance in this task was used as one of the screening criteria for participants' recruitment. Thus, it remains unclear whether adults with poor reading comprehension necessarily share this deficit in reading of German.

An additional publication on adults with low literacy skills who read German provides insight into the measures of accuracy in visual processing of single words and pseudowords. Boltzmann and Rüsseler (2013) applied a task, in which adults with low literacy skills were asked to detect repetitions of words or pseudowords that were presented one after the other on a computer screen. On average, participants showed a high accuracy rate (a mean of $88.56 \%, S D=13.08$ in 17 participants assigned to an experimental group and a similar accuracy rate of $90.45 \%, S D=61$ in 10 participants assigned to a control group). Notably, accuracy in recognizing repetitions of pseudowords (a task involving decoding) was somewhat lower, but still above $80 \%$. At the same time, considering that the words were concrete nouns referenced from schoolbooks for first-graders, and that participants read a transparent orthography, the error rates in this study may not be without importance. These findings, which were based on a small sample and on a repetition detection task, justify a closer examination of whether accuracy in word and pseudoword reading constitutes a source of difficulty in adults with low literacy skills who read German.

As far as the reading-related oral language skills are concerned, Grosche and Grünke (2011) reported a disadvantage in phonological awareness (as well as in phonological working memory) when participants, in their study of German speaking adults with low literacy skills, were compared to both chronological-age and reading-level matched controls $(n=54$ in each group). These researchers also found inferior RAN scores in the adult sample compared to the chronological-age controls, but better scores compared to the reading-level matched children.

\section{Contribution of the present study}

In view of the scarce investigation of adults with low literacy skills who struggle with reading transparent orthographies, we wish to contribute to the understanding of the basic reading and some of the reading-related oral language skills of these adults. We complement previous data in the following aspects: first, studies on 
adults with low literacy skills vary considerably in their screening criteria. Some studies included all participants in an adult literacy program (e.g. Braze et al., 2016). In other studies, performance in basic measures of reading, such as word reading, were used to screen participants (Greenberg et al., 1997; Grosche \& Grünke, 2011). In the present study, we were interested in exploring the skills of adults who share a low level of reading comprehension, which is a core aspect describing the functionality of reading (Egloff et al., 2011). We therefore screened participants according to achievements in a reading comprehension test. Second, in order to understand whether the poor reading comprehension of the population in focus necessarily goes together with deficits in basic skills of reading, we carried out two types of analyses: (a) We compared the average performance of the entire sample in these skills to expected norms. (b) We explored the frequency of cases at four levels of performance in relation to the norms (at or below the 10th percentile, between the 11th and 25th percentiles, between the 26th and 75th percentiles and at or above the 76th percentile). Finally, the previous studies of German readers with low literacy skills used a standardized word reading task which was designed for children. If performance of adults is lower than that expected from children, then deficits are assumed. However, if it is higher, the interpretation of the results remains unclear. In the present investigation we, therefore used standardized decoding and word reading tests which allow mapping performance according to norms of different age groups, including those of adults.

\section{Research questions and hypotheses}

We addressed two questions: The first, do adults with low reading comprehension, who read the German orthography, show deficits in the fluency of decoding and word reading, in text reading rate, in phonological awareness and in RAN when compared to norms of adults and of children? The literature reviewed above led us to hypothesise that participants would present, as a group, deficits in these measures. The second question was whether accuracy in decoding and in word reading (when presented in isolation or in context) constitutes a source of difficulty in adults who struggle with reading German orthography. Reading accuracy in the present sample was expected to be high, in view of the findings on near-perfect to perfect accuracy rates in children learning to read transparent orthographies (including in children with a reading disability, e.g. Wimmer, 1993).

\section{Methods}

\section{Participants}

A sample of 54 participants (33 men) with poor reading comprehension was selected from a larger database previously collected from 191 adults attending basic education courses or vocational training programs (Vágvölgyi, 2018). The basic education courses had a major focus on improving reading and writing skills. Accordingly, we 
turned to them in order to recruit participants with low literacy skills for our study. Notably, reading and writing are not the only focus of these courses (which often also include basic calculation, health, and financial literacy). The vocational trainings further offered courses in specific professions (e.g. office management). We turned to these schools in view of the PISA data, which indicate a much higher proportion of students reaching the lowest levels of reading competencies among students attending schools that do not lead to high-school graduation (29\%) in comparison to schools leading to high-school graduation (2\%, see Reiss et al., 2019).

The selection process included several steps. First, only participants with poor performance in a standardized text comprehension task (ELFE 1-6, Lenhard \& Schneider, 2006) were selected. In the absence of a clear criterion defining deficient reading comprehension among adults, and while considering that in many countries primary education includes the first six grades, we placed the cut-off point at percentile 28.6 or below, according to norms of 6th graders in this task. Notably, the suggested cut-off point indicating possible problems in reading skills is the 25 th percentile. However, the norms of the subtest applied in the present examination do not allow the setting of a cut-off point at exactly the 25 th percentile (the completion of 13 answers out of 20 items included in the test is placed at percentile 22.3, and the completion of 14 answers out of 20 items is already placed at percentile 28.6). Considering that the test was designed for students up to the 6th grade, and that in the current study adults were tested, we referred to the higher cut-off point of 14 correct answers (i.e. to percentile 28.6). Notably, when performance was compared to the norms of 4 th graders, $66.6 \%$ of the participants in the sample showed a reading comprehension score that was below the 25th percentile. None of the participants reached a score that exceeded percentile 36.2 according to these norms.

Second, in order to exclude cases, in which deficient reading comprehension could be explained by insufficient knowledge of the German language due to a migration background, only participants who were born in Germany were selected. Third, participants with a below average non-verbal processing speed (according to the LPS-2 test's norms; Kreuzpointner et al., 2013) were also excluded, as low general ability may in itself explain deficient text comprehension. Notably, non-verbal processing speed is a central component of IQ and accordingly shows significant correlations with different dimensions of general ability (LPS-2, Test manual, Kreuzpointner et al., 2013). Fourth, participants reporting diagnoses of hearing deficits, uncorrected sight problems or an attention deficit were also excluded. This selection process resulted in the sample of 54 participants, whose data were analyzed.

Participants had a mean non-verbal IQ approximation score based on the nonverbal speed of processing test of $90.72(S D=9.59)$. Further characteristics of the sample were collected in a short interview as described in the Procedure section. The mean age of participants in this sample was $26.17(S D=16.06)$. Other questions included in the interview were mostly category based. Accordingly, Table S1 in the Supplemental Material presents the frequency per response category in these questions. Participants spent 8 to 12 years in the formal educational system (with a mean of $10.57, S D=1.09$ years), while 31 participants repeated a class or more than one class. Most were unemployed at the time of testing. Finally, 23 participants reported 
having a first language other than German. However, the vast majority of the sample reported speaking German at home during the school years and also today.

Notably, we did not exclude participants who spoke a first language other than German, as they all had an opportunity to attend the German educational system from an early age. Setting the place of birth as an exclusion criterion, rather than the first language appeared to be sufficient in order to exclude participants who did not master the German language to a sufficient degree in order to allow the understanding of texts designed for first to sixth graders. Nevertheless, we compared performance in the reading and reading-related tasks of participants who speak German as a first language and participants who speak German as a second language (using the non-parametric Mann-Whitney test). The two groups tended to differ in reading comprehension, while significant differences were obtained in fluency, word reading and decoding, as well as in text reading rate (Table S2 in the Supplemental Material). Interestingly, the group with a first language other than German showed some advantage. As the study was not originally planned to systematically compare the two groups, these results do not shed light on the role of language background in literacy skills in adulthood. Such a comparison would necessitate more information on the use of the first and second languages in different contexts, as well as a careful matching between the two groups in measures other than written language competencies. The current comparison could only suggest that having a first language other than German did not result in a clear disadvantage of the participants in the literacy skills in the tested group.

\section{Materials}

\section{Non-verbal speed of processing}

Subtest three from the German standardized non-verbal intelligence test Leistungsprüfsystem 2 (LPS-2, Performance Testing System, Kreuzpointner et al., 2013) was administered. Participants were required to mark one symbol that did not match a row of symbols within a limited time. It may be noted, that the subtest correlates significantly with different dimensions of intelligence (crystalized intelligence, fluid intelligence, visual perception and cognitive speed), with correlations ranging from $r=.28$ to.76 (Test Manual, Kreuzpointner et al., 2013). The raw scores were converted into an IQ score based on the guidelines provided in the manual. As a full IQ assessment was not carried out in this study, we refer to this score as a non-verbal IQ approximation score. The test reliability coefficients are between $r=.77$ and $r=.89$.

\section{Reading comprehension}

The subtest of text reading from the Leseverständnistest für Erst- bis Sechstklässler (ELFE 1-6 Test, Reading Comprehension Test for 1st to 6th graders, Lenhard \& Schneider, 2006) was administered. The rationale guiding the choice of this test was the following: The task examines the understanding of very short texts (up to four sentences in length). Other standardized reading comprehension tests with norms, 
which were designed for older students examine the understanding of longer and more complex texts. Such tasks may be too difficult for adults with low literacy skills and result in floor effects. As in the ELFE 1-6 test, the same set of texts were designed for readers between the 1st and the 6th grades, we estimated that this task would better capture the variance within a group of adults, whose reading comprehension skills are expected to be very low. It may be noted, that we did not observe ceiling effects.

In the selected subtest of text reading, participants were required to read 20 short paragraphs and answer multiple-choice comprehension questions within a limited time of six minutes. Two examples preceded the subtest and the participants earned one point for each item answered correctly. Cronbach's alpha reliability coefficients of the subtest is .92 .

\section{Decoding and word recognition}

Two subtests from the standardized Salzburger Lese-und Rechtschreibtest II (SLRTII; the Salzburg Reading and Spelling Test, Moll \& Landerl, 2010) were administered. These were decoding of pseudowords and reading of single words. Each subtest comprised a list of 156 items (nouns and verbs in the case of the word-reading test). Participants were asked to read aloud, as fast and as accurately as they could and were stopped after one minute in each subtest. The correct reading of a word/ pseudoword was scored with one point per item. Reliability coefficients of the subtests are between .90 and .98 .

\section{Text reading}

Text number six from the standardized Zürich Lesetest II (ZLT-II; the Zürich Reading Test, Petermann \& Daseking, 2013) was used in order to examine word reading in context. The text was designed for 7 th-8th graders and included 156 words. Participants were asked to read aloud as fast and as accurately as they could. No comprehension questions were presented. The test reliability is $r=.72$.

\section{Phonological awareness}

Two subtests from the standardized Basiskompetenzen für Lese-Rechtschreibleistungen test were administered (BAKO 1-4; Basic Competencies for Reading and Spelling Skills, Stock et al., 2003). In the Phoneme Interchange subtest, participants were required to switch between the first phonemes of given words or pseudowords (which were spoken from an audio recording) and to say the new word out loud (e.g. ilma, lima). Eleven items were included in this subtest. In the Word Reverse subtest, which included 18 items, participants were asked to say given words or pseudowords in a reverse order of their phonemes (e.g. sabe, ebas). One point was given for each item correctly manipulated. Reliability coefficient of the Phoneme Interchange subtest is .75 and of the Word Reverse subtest is .82 (both coefficients relate to data of 4th graders). 


\section{RAN}

Two subtests from the Züricher Lesetest II (ZLT-II; the Zürich Reading Test, Petermann \& Daseking, 2013) were administered, both required fast naming of pictures of familiar objects. The first (RAN 1 task) included the pictorial presentation of five objects: a fish, a car, a heart, glasses and a sun. Their appearance was repeated 30 items (in five columns and six rows). In the second subtest (RAN 2 task), 30 different objects (e.g. arrow, fork, door, tree, pear, foot, apple, balloon, tooth, ear) were presented in a matrix of five columns and six rows (without repetition). Reliability coefficients are $r=.94$ and $r=.89$ for the two tasks, respectively.

\section{Procedure}

The tasks were presented in the same order for all participants. Parallel forms were available for some tests (reading comprehension, reading of pseudowords and of words and speed of processing). In these cases, participants were randomly assigned into one of the two versions of the tests. The testing took place at the participants' schools. Background information on participants (including information about first language, language spoken at home during the school years and today, number of years in formal education, employment status and prior diagnoses of learning disabilities and neurological conditions) was collected in an oral interview, lasting about 5-7 min. The participants gave their informed consent to take part in the study, and the basic education participants were payed at the end of the testing process $(75 €)$. Participants from vocational trainings could not be paid. Instead, a sum of $150 €$ was given to their class.

\section{Results}

\section{Descriptive statistics and relations between variables}

The average raw data and standard deviations of the reading and reading- related skills are presented in Table 1, and the distributions of scores in these measures are presented in Figure 1, Figure 2, Figure 3 and Figure 4 (Supplemental Material). The relations of the basic reading and reading-related language skills with reading comprehension were tested using a Pearson correlation analysis (Table 2). All measures showed medium to high correlations with reading comprehension except for the RAN measures.

\section{Performance in the basic reading and reading-related language tasks in relation to available norms}

In order to evaluate the level of performance in the different skills in relation to the level expected by different age groups, the raw scores were converted into 
Table 1 Descriptive statistics of the reading and reading related measures

\begin{tabular}{lrr}
\hline & Mean & \multicolumn{1}{c}{ SD } \\
\hline ELFE 1-6 reading comprehension (correct out of 20) & 10.48 & 3.43 \\
SLRT-II decoding fluency $^{\mathrm{a}}$ & 45.76 & 21.89 \\
SLRT-II decoding errors (\%) $^{\mathrm{a}}$ & 10.31 & 15.83 \\
SLRT-II word reading fluency $^{\mathrm{a}}$ & 77.02 & 26.17 \\
SLRT-II word reading errors (\%) & 3.86 & 5.67 \\
ZLT-II text reading errors (\%) & 6.82 & 6.14 \\
ZLT-II text reading time in seconds & 118.46 & 50.20 \\
BAKO 1-4 PA: Phoneme Interchange (correct out of 11) & 7.17 & 4.02 \\
BAKO 1-4 PA: Word Reverse (correct out of 18) & 11.22 & 6.61 \\
ZLT-II RAN 1 time in seconds & 20.28 & 3.98 \\
ZLT-II RAN 2 time in seconds & 28.85 & 6.09 \\
\hline
\end{tabular}

$P A$ phonological awareness, $R A N$ rapid naming

${ }^{\mathrm{a}}$ Correct items in $1 \mathrm{~min}$

percentiles or percentile ranges based on the available norms. Details on these norms and the specific age-groups used to compare the raw scores are presented in Table 3. First, the norms of the oldest group available in the tests' manuals were referred to. Additionally, the norms of 6th graders were used (if they were available), as low performance in the reading comprehension test related to 6th graders' norms, was the inclusion criterion of the current sample. We also referred to the expected performance by 4th graders, as this is the final grade of primary schools in most federal states of Germany.

In order to address the first research question, we evaluated the average performance of the entire group in relations to the norms (Table 4). To this end, the raw averages in the different reading and reading-related measures were converted to the percentiles or percentile ranges. The results indicated very poor achievements in the tasks measuring fluency in decoding and in word reading, when the average raw scores were compared to norms of adults (scores were at the 7th-10th percentile range in decoding and at the 1st-5th percentile range in word reading). The average raw scores in these measures were also low in comparison to norms of 6th graders (at the 21st-29th percentile range in decoding and the 21st-24th percentile range in word reading), but within the normal range in comparison to norms of 4th graders (at the 57th-62nd percentile range in decoding and the 53rd-58th percentile range in word reading). The average performance in the measure of text reading rate was very low, corresponding to the 1 st-5th percentile range of norms of 8th graders.

As far as the reading-related oral language skills are concerned, the average achievements in the tasks of Phoneme Interchange and Word Reverse were at the 22nd and the 36th percentiles, respectively, when achievements were compared to norms of 4th graders (i.e. the norms of the oldest group available in this tests' norms). Performance in the RAN time measure could be compared to two groups of young (1st-4th graders) and of older (5th-8th graders) students. The average 


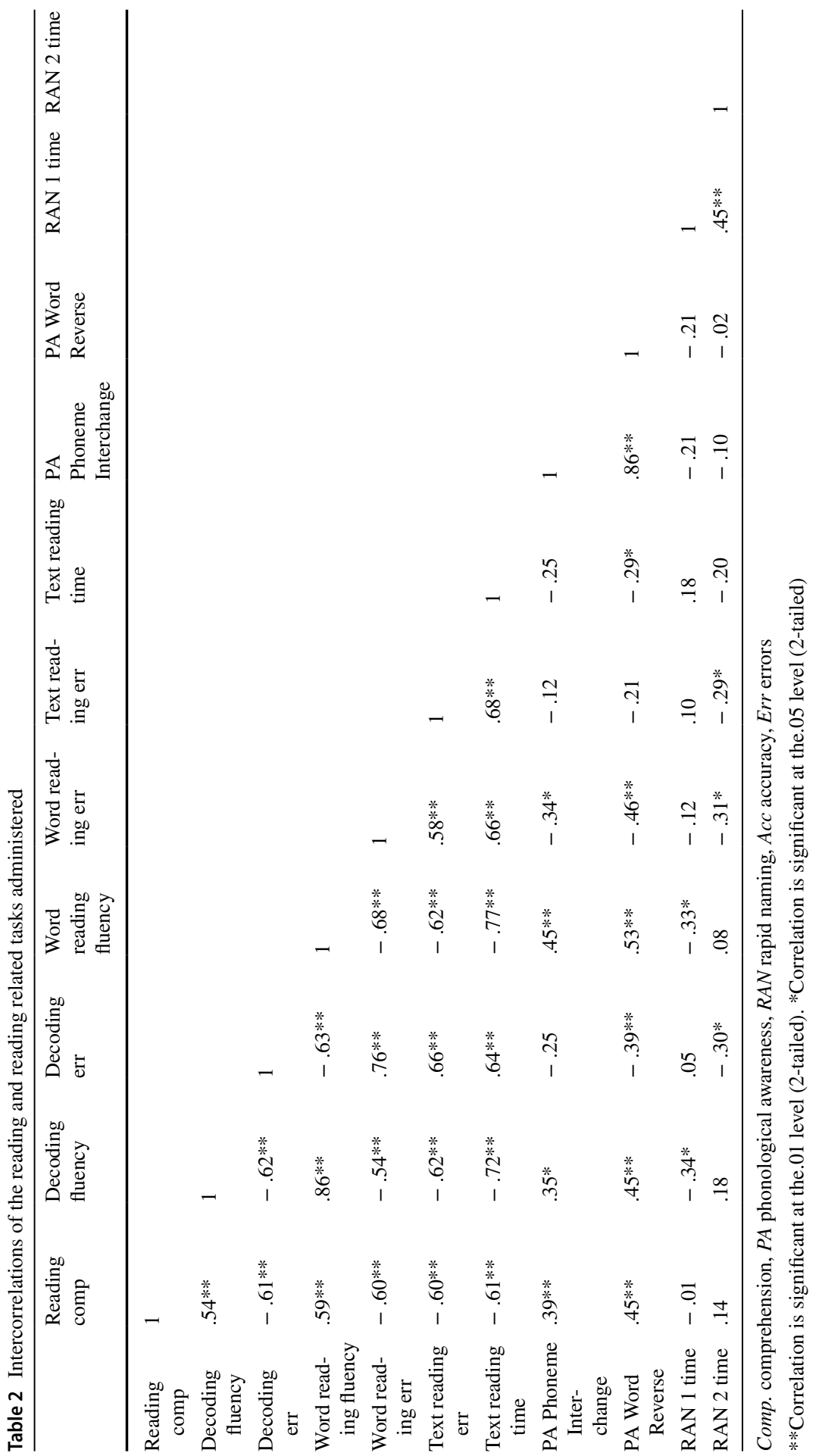


Table 3 Tests applied and available norms

\begin{tabular}{|c|c|c|c|}
\hline & Test & Available norms & $\begin{array}{l}\text { Norms used for compari- } \\
\text { son of performance }\end{array}$ \\
\hline Reading comprehension & ELFE $1-6$ & Grades $1-6$ & Grade $6^{\mathrm{a}}$, grade 4 \\
\hline Decoding & SLRT II & Grades $1-6$, adults & ${ }_{4}$ Adults $^{\mathrm{b}}$, grade $6^{\mathrm{c}}$, grade \\
\hline Word recognition & SLRT II & Grades $1-6$, adults & Adults $_{4}^{\mathrm{b}}$, grade $6^{\mathrm{c}}$, grade \\
\hline Text reading & ZLT II & Grades 7-8 & Grade 8 \\
\hline Phonological awareness & BAKO 1-4 & Grades $1-4$ & Grade 4 \\
\hline RAN & ZLT II & Grades $1-4$, grades $5-8$ & Grades $1-4$, grades $5-8$ \\
\hline
\end{tabular}

${ }^{\mathrm{a}}$ The norms represent various school types (those leading to a high-school graduation and those not leading to high-school graduation)

${ }^{\mathrm{b}}$ The norms were based on young adults, including students in high school, university and vocational trainings

${ }^{\mathrm{c}}$ The norms represent children in schools not leading to a high school graduation (according to the German system, Realschule and Hauptschule)

Table 4 Mean performance according to norms in percentiles or percentile ranges

\begin{tabular}{|c|c|c|c|}
\hline & Minimum & Maximum & Mean \\
\hline ELFE $1-6$ reading comprehension (4th graders' norms) ${ }^{\mathrm{a}}$ & $<1$ & 36.20 & 19.40 \\
\hline SLRT-II decoding fluency (adults' norms) & $<1$ & $78-81$ & $7-10$ \\
\hline SLRT-II decoding fluency (6th graders' norms) & $<1$ & $>97$ & $21-29$ \\
\hline SLRT-II decoding fluency (4th graders' norms) & $<1$ & $>98$ & $57-62$ \\
\hline SLRT-II word reading fluency (adults' norms) & $<1$ & $42-62$ & $1-5$ \\
\hline SLRT-II word reading fluency (6th graders' norms) & $<1$ & $>95$ & $21-24$ \\
\hline SLRT-II word reading fluency (4th graders' norms) & $<1$ & $>98$ & $53-58$ \\
\hline ZLT-II text reading errors (8th graders' norms) & 0.999 & $76-100$ & $16-25$ \\
\hline ZLT-II text reading time (8th graders' norms) & 0.999 & $76-100$ & $1-5$ \\
\hline BAKO 1-4 PA Phoneme Interchange (4th graders' norms) & 0.00 & 95.00 & 22 \\
\hline BAKO 1-4 PA Word Reverse (4th graders' norms) & 1.00 & 96.00 & 36 \\
\hline ZLT-II RAN 1 time (5th-8th graders' norms) & $1-5$ & $76-100$ & $26-50$ \\
\hline ZLT-II RAN 1 time (1st-4th graders' norms) & $16-25$ & $76-100$ & $51-75$ \\
\hline ZLT-II RAN 2 time (5th-8th graders' norms) & $1-5$ & $76-100$ & $26-50$ \\
\hline ZLT-II RAN 2 time (1st-4th graders' norms) & $16-25$ & $76-100$ & $51-75$ \\
\hline
\end{tabular}

$P A$ phonological awareness, $R A N$ rapid naming

${ }^{a}$ The ELFE 1-6 test was used as a screening test. Participants were included in analysis provided they showed a text reading comprehension score at or below the 28.6 percentile according to norms of 6 th graders 
raw scores were above the 25 th percentile in comparison to the norms of both groups.

In an additional analysis, we examined to which extent the participants shared the deficits suggested by the averages presented in Table 4. To this end, we tested the proportion of participants performing at four levels in relations to the norms. We created these levels by relating to the criteria often used in diagnostic tests to describe performance: (1) at a very low level (at or below the 10th percentile); (2) at a level below the average range (11th to 25th percentiles); (3) at the average range (26th percentile to the 75 th percentile); (4) and at a level which exceeds the

Table 5 Proportion of participants (in \%) according to performance level

\begin{tabular}{|c|c|c|c|c|}
\hline & $\leq 10$ th percentile & $\begin{array}{l}11 \mathrm{th}-25 \text { th } \\
\text { percentiles }\end{array}$ & $\begin{array}{l}26 \text { th- }-75 \text { th } \\
\text { percentiles }\end{array}$ & $\geq 76$ th percentile \\
\hline \multicolumn{5}{|c|}{ ELFE $1-6$ reading comprehension ${ }^{\mathrm{a}}$} \\
\hline 4th graders' norms & 29.6 & 37.0 & 33.3 & - \\
\hline \multicolumn{5}{|l|}{ SLRT-II decoding fluency ${ }^{b}$} \\
\hline Adults' norms & 57.4 & 22.2 & 18.5 & 1.8 \\
\hline 6th graders' norms & 31.5 & 11.1 & 37.0 & 20.4 \\
\hline 4th graders' norms & 24.1 & 3.7 & 24.1 & 48.1 \\
\hline \multicolumn{5}{|c|}{ SLRT-II word reading fluency ${ }^{b}$} \\
\hline Adults' norms & 77.8 & 7.4 & 14.8 & - \\
\hline 6th graders' norms & 35.2 & 7.4 & 40.7 & 16.7 \\
\hline 4th graders' norms & 14.8 & 9.3 & 33.3 & 42.6 \\
\hline \multicolumn{5}{|l|}{ ZLT-II text reading errors } \\
\hline 8th graders' norms & 25.0 & 17.3 & 36.5 & 21.1 \\
\hline \multicolumn{5}{|l|}{ ZLT-II text reading time } \\
\hline 8th graders' norms & 53.8 & 13.5 & 26.9 & 5.8 \\
\hline \multicolumn{5}{|c|}{ BAKO 1-4 PA phoneme interchange } \\
\hline 4th graders' norms & 22.2 & 24.1 & 13.0 & 40.7 \\
\hline \multicolumn{5}{|l|}{ BAKO 1-4 PA word reverse } \\
\hline 4th graders' norms & 20.4 & 16.7 & 24.1 & 38.9 \\
\hline \multicolumn{5}{|l|}{ ZLT-II RAN 1 time } \\
\hline 5th-8th graders' norms & 5.6 & 18.5 & 64.8 & 11.1 \\
\hline 1th-4th graders' norms & - & 5.6 & 48.1 & 46.3 \\
\hline \multicolumn{5}{|l|}{ ZLT-II RAN 2 time } \\
\hline 5th-8th graders' norms & 3.7 & 14.8 & 66.7 & 14.8 \\
\hline 1th-4th graders' norms & - & 1.9 & 44.5 & 53.6 \\
\hline
\end{tabular}

$P A$ phonological awareness, $R A N$ rapid naming

${ }^{\mathrm{a}}$ The ELFE 1-6 test was used for the purpose of screening

${ }^{\mathrm{b}}$ The SLRT II test provides norms in the form of percentile ranges. In some cases, the cut-off points defining each level of performance (the 10th percentile, the 25 th percentile and the 76 th percentile) fell within a percentage range. In these cases, the range including these percentiles were referred to as the relevant cut-off points 
average range (at or above the 76th percentile). The results of this analysis appear in Table 5 .

When the raw data of fluency in decoding and in word reading were compared to norms of adults, the scores of most of the participants $(57.4 \%$ in the case of decoding and $77.8 \%$ in the case of word reading) fell at or below the 10 th percentile. This was also the case when text reading rate was compared to norms of 8 th graders, with $53.8 \%$ of the participants performing at or below the 10th percentile. The achievements of a considerable proportion of the sample were at or below the 10th percentile, also when fluency in decoding and in word reading were compared to norms of children in the 6th and the 4th grades (see Table 5).

Frequency analyses were carried out in order to examine whether or not participants with scores above the 25 th percentile had grouped closely to this percentile (Table S3 in the Supplemental Material). These analyses did not indicate a grouping above the 25th percentile, when the decoding and word reading fluency scores were compared to norms of adults and when the text reading rate was compared to norms of 8th graders.

Notably, as the sample included both participants who speak German as a first language and participants who speak German as a second language, we also explored the representation of each of these groups at the lowest level of performance in the reading tasks (performance at or below the 10th percentile). As can be observed in Table S4 (Supplemental Material), between 17.4 and 78.3\% (depending on the reading task) of the participants who speak German as a second language performed at this level, and of the participants who speak German as a first language-between $29 \%$ and $77.4 \%$ performed at this level. Participants speaking German as a second language do not appear to have been over represented in our sample at the lowest level of performance. It should be stressed, however, that due to the fact that the groups differing in their first language were not matched on other factors (e.g. in reading experience) in advance, this comparison should be treated with great caution. The distribution of participants at the lowest level of performance in the reading tasks across further background categories is presented in Table S4 (Supplemental Material).

As far as phonological awareness is concerned, despite the fact that norms of 4th graders were used as a reference point, $46.3 \%$ and $37.1 \%$ of the participants performed at or below the 25th percentile in the Phoneme Interchange and the Word Reverse tasks, respectively. A considerable proportion of these adults even performed at or below the 10th percentile $(22.2 \%$ in the task of Phoneme Interchange and $20.4 \%$ in the task of Word Reverse). Interestingly, an inspection of the raw data indicated that $38.9 \%$ of the sample correctly completed all 11 items in the Phoneme Interchange task and the same proportion of participants correctly completed all 18 items of the Word Reverse task.

The proportion of participants whose naming speed was below the average range was smaller in the RAN tasks compared to the other tasks, while most participants performed within the normal range when naming time was compared to the norms of 5 th to 8th graders. A very small proportion of participants presented a naming speed score which was below the 10th percentile according to norms of 5th to 8th graders $(5.6 \%$ and $3.7 \%$ in the two naming tasks). Very few participants also showed naming speed below the 25th percentile when their performance was compared to the norms of 4th graders (5.6\% and $1.9 \%$ of the participants in the two naming tasks). 


\section{Accuracy in reading}

In the absence of available norms for accuracy in decoding and in reading of single words, the analysis of these measures was based on error rates. As indicated in Table 1 , the average error rate was $10.31 \%$ in decoding and $3.86 \%$ in word reading. The average error rate in the text reading task was $6.82 \%$. This latter task, in contrast to the decoding and word reading tasks, included norms for reading errors. When compared to norms of 8th graders, the group average error rate in text reading was at the 16th-25th percentile range (Table 4), while the performance of $25 \%$ of the sample was at or below the 10th percentile (Table 5).

A possible advantage for accuracy in reading of single words over decoding and text reading was further tested using a repeated measure ANOVA analysis. The three measures of error rates (in word reading, decoding and text reading) were entered as within-participant variables. A main effect was found for type of test $(F(1.29,65.92)=8.246, p=.003$, partial eta square $=.139)$. Bonferroni pair-wise comparisons indicated a significant advantage in accuracy in single word reading compared to decoding $(p=.002)$ and text reading $(p=.001)$.

\section{Discussion}

The aim of this study was to describe the basic reading and some reading-related oral language skills of a sample of adults with low reading comprehension, who read transparent German orthography. We first discuss performance in these skills in relation to the norms, and then refer to reading accuracy.

\section{Evaluation of performance in relations to the norms}

We hypothesized that the focus group would present low scores in all skills tested. When considering the analysis of the group averages, this hypothesis was confirmed in the case of the basic reading skills. Namely, the average decoding and word reading fluency skills of the adults in the sample were extremely poor in comparison to norms of adults (at the 7th-10th and at the 1st-5th percentile ranges, respectively). The average performance in these skills was also low in comparison to norms of 6th graders, but within the normal range of 4th graders. In addition, the average text reading rate was extremely low (at the 1st-5th percentile range according to norms of 8th graders). The evaluation of the reading-related oral language skills was more restricted in comparison to the analysis of the basic reading skills, due to lack of age-appropriate norms. Nevertheless, this analysis indicated that the mean scores in the phonological awareness tasks were somewhat lower than the average expected from 4th graders (scores were at the 22nd and 36th percentiles, depending on the phonological awareness task). These results are in line with reports from previous studies on adults with low literacy skills who read English orthography or more transparent orthographies, including German (Boltzmann et al., 2017; Eme et al., 2014; Grosche \& Grünke, 2011). 
The average RAN scores did not, however, indicate a deficit when compared to norms of 5 th to 8 th graders, as the mean performance was at the 26 th-50th percentile range. In the absence of norms of adults, these findings may only suggest that participants reach on average the level expected from adolescents. Similarly, the findings by Grosche and Grüne (2011) suggest that the RAN skills of German speaking adults with low literacy skills are between the level expected from children and the level expected from adults. At the same time, in the present investigation RAN and reading comprehension did not correlate. Consequently, the present results do not support the possibility that RAN has a role in explaining deficient comprehension in adults. It may also be noted, that a meta-analysis based on 16 studies of low literate adults indicated a considerable variance in the correlations between RAN and reading comprehension, with an overall weak relation $(r=.15$, Tighe \& Schatschneider, 2016), which seems roughly in line with the present data. As the relation between reading and RAN has been widely established for children (Araújo et al., 2015), the current results may be explained by the somewhat inconsistent nature of relations of object-naming and reading across different age groups, as reported by van den Bos, Zijlstra and Spelberg (2002). In their study, significant correlations between the naming of pictures and reading were obtained at the ages of 8,12 and 16 years, but not at the ages of 10 and 46 years. More consistent relations were, however, found between reading and naming of alphanumeric symbols.

When the results were, however, evaluated according to the proportion of participants performing at different levels, a more complex picture emerged. When the raw scores in decoding and in word reading fluency were compared to norms of adults, performance of the vast majority of the sample fell at or below the 25 th percentile (while most performed at or below the 10th percentile). Nonetheless, a considerable proportion of the sample performed above the 25 th percentile in these measures $(20.3 \%$ of the participants in the case of decoding and $14.8 \%$ of the participants in the case of word reading). The variance in text reading was also remarkable, as $32.7 \%$ of the sample presented a text reading rate above the 25 th percentile according to 8th grade norms. These results suggest that poor reading comprehension in adults who read German does not necessarily imply deficits in fluency in the basic skills of reading. Altogether, these data are consistent with the notion that low literacy skills in adults may be heterogenous, as previously demonstrated by Mellard et al. (2010) in a large sample of readers of English.

Notable variance was also observed in phonological awareness. While a rather high frequency of adults showed performance at or below the 25 th percentile when compared to the available norms (46.3\% and 37.0\%, depending on the task), a similar proportion of participants also reached perfect performance in the two phonological awareness tasks (38.9\% in each of these tasks). As mentioned in the introduction, phoneme awareness has been found to develop earlier in readers of transparent orthographies in comparison to readers of opaque orthographies and orthographic transparency was also suggested to facilitate the acquisition of phoneme awareness in children with a reading disability (Goswami et al., 2005; Wimmer, 1993). At the same time, a phonological deficit has been found 
in children with a reading disability, independent of whether they learned to read in English or German (Landerl et al., 1997). Whether the phonological deficit of some of the adults in the present investigation can be explained by a reading disability remains unclear. Nevertheless, the present results suggest that phonological awareness is a continuous difficulty for some struggling readers of German, despite reading a transparent orthography.

\section{Evaluation of accuracy in reading}

We assumed that due to the transparent nature of the spelling-sound relations in German, reading accuracy would be high. The error rates in word reading were low (3.86\%), but significantly higher in decoding (10.31\%) and in text reading $(6.82 \%)$. This latter error rate proved to be deficient when compared to the available norms (of 8th graders). Nevertheless, significant variance between participants was evident, as the accuracy rate in the text-reading task of more than half of the participants in the sample $(57.6 \%)$ was above the 25 th percentile according to the norms.

Children learning to read German were found to reach an accuracy rate of around $98 \%$ in reading of words and around $95 \%$ in decoding in the course of the first grade (Seymour et al., 2003). It has even been found that children with a reading disability can quickly achieve high accuracy rates in reading German. Wimmer (1993) for example, reported $92 \%$ of accuracy in decoding, and a near perfect accuracy in word reading (97-100\%, depending on word type) and text reading (99\%) in a sample of German readers with a reading disability in the 3 rd and 4th grades. The accuracy rates found in the present study may then be somewhat lower (particularly in the reading of text) than would be expected from adult readers of a transparent orthography, even in the presence of a reading difficulty. Limited print exposure and distance from formal education may all explain these results. These comparisons between studies should, however be treated with caution, as different reading tests were applied. Nevertheless, when considering the present results, our expectation to see high reading accuracy rates appears to be confirmed, but with some reservation. On the one hand, the absolute error rates were indeed low. On the other hand, the misreading of 10-11 words in a text of 156 words (as indicated by the $6.82 \%$ error rate in text reading) may still considerably impede reading comprehension.

It should further be considered that participants showed higher error rates in decoding than in single word reading. Decoding is expected to lean to a larger extent on phonological processing compared to the reading of real words, which may already be familiar to the readers by their orthographic pattern. These data accord with previous research, indicating an advantage of adults with low literacy skills in orthographic reading strategies in comparison to phonological strategies (Greenberg et al., 2002; Thompkins \& Binder, 2003).

\section{A practical perspective}

The present results from readers of German in combination with previous findings from readers of English (e.g. Greenberg et al., 1997) suggest that the basic skills of 
reading, i.e. decoding and word recognition, should be addressed in literacy classes for adults. As would be expected from struggling readers of a transparent orthography, the reading fluency measures constituted a considerable difficulty for the vast majority of the participants in the present sample. Nevertheless, the current results concurrently suggest, that addressing accuracy in reading should not be neglected.

However, it is yet unclear how the fundamental skills of reading should be addressed in adults with low literacy skills. Decoding skills are systematically taught in the very early grades of primary school (usually in the 1st grade). Accordingly, research on the effectiveness of the instruction of basic reading skills is far more established in children than in adults. Furthermore, the scarce research on the effects of reading instruction in adult literacy classes points to significant challenges in obtaining considerable progress, despite taking into account basic reading skills (including decoding) as well as higher order skills (e.g. reading comprehension) as targets of intervention (Greenberg et al., 2011). More research is clearly needed in order to identify the multiple factors affecting instruction of adults with low literacy skills. For example, Greenberg et al. (2011) point to the problem of applying instructional programs, which were successfully applied in children, because these programs were not originally designed to address long years of inefficient reading habits. More instructional time may need to be allocated for the automatization of basic reading processes (e.g. accuracy and fluency in grapheme-phoneme conversion) in trying to overcome previously established, inefficient reading routines.

The present results also highlight the need to consider the heterogeneity of participants when developing an academic lesson for a literacy class. Even if participants share characteristics, which had served for the screening process of the current sample, the instruction program may have to be compatible for a spectrum of needs. While some may have to build their skills from the very basic foundations of reading, others may need to improve different reading-related skills. This situation may necessitate a thorough evaluation of skills at the beginning of a literacy course-a process which is not yet routinely integrated in such settings. Such an evaluation would allow for the development of indivualized learning programs, based on each person's reading abilities and deficits.

Finally, it may be noted, that the heterogeneity of the sample further raises the question of generalizability of the results. Literacy classes are open to the wide public of adults, regardless of factors such as age, education or language background. The heterogeneity of the current sample may then reflect a common composition of adult learners in these classes. At the same time, whether and how the background factors of an adult learner should be considered in the planning of the individual instruction requires further examination.

\section{Limitations of the study}

The limitations of the study are further considered. First, the availability of standardized tests, which could be administered to adults with low literacy skills, is restricted and hence requires certain compromises. Consequently, some of the tests lacked norms for adults. Considering, for example that $38.9 \%$ of the sample reached 
a perfect accuracy score in the phonological awareness task leaves the possibility that this task was not sensitive enough to capture the variance in phonological awareness skills expected from adults. Note, however, that the ELFE 1-6 reading comprehension test (Lenhard \& Schneider, 2006) used to screen participants in the present investigation, did not result in ceiling effects, although it was designed for 1 st to 6 th graders. On the contrary, the participants in our sample scored low in this test, even when compared to norms of 6th graders. Second, while attempting to control for a large variance in adults with low literacy skills, we analyzed a sub-group drawn from a larger database according to certain common criteria. This left a rather small group of 54 adults with a broad age range. A third limitation of the study is that only one type of RAN task was used-naming of objects. However, previous studies suggest that RAN of digits and numbers may show stronger relations with reading (Bowey, 2005; van den Bos et al., 2002). Finally, the study included limited information on the social and educational background of the participants. As a result, the study does not allow exploring the possible sources of variance found in the basic reading and reading-related skills. In a similar vein, despite the fact that we did not find a disadvantage in the reading and reading-related skills of participants who speak German as a second language in comparison to participants who speak German as a first language, the possibility that first language plays a role in poor literacy skills in adulthood cannot be ruled out. An understanding of the role of the background measures and particularly of the language background in literacy skills in adulthood requires a separate examination with a dedicated design.

\section{Conclusions}

To conclude, the current results indicate that poor performance in fluency of decoding and word reading, in text reading rate and in phonological awareness can be found, on average, in a sample of adults with low reading comprehension skills who read German orthography. Nevertheless, the results also indicate that a deficit in reading comprehension in this population does not necessarily imply deficits in the basic skills of reading. The data further suggest that accuracy in reading constitutes a source of difficulty for some of these readers, despite reading a transparent orthography.

Supplementary Information The online version contains supplementary material available at https://doi. org/10.1007/s11145-021-10147-4.

Acknowledgements Data were collected as part of a research entitled "Basic Foundations of Functional Illiteracy". The research was funded by the LEAD Graduate School \& Research Network [GSC1028], a project of the Excellence Initiative of the German federal and state governments and by the German Institute for Adult Education-Leibniz Centre for Lifelong Learning e.V. We would like to thank the schools, teachers and participants for their cooperation, as well as the research assistants (Antonia Restemeier, Galina Burdukova, Franziska Sohn, Philipp Just, Isabel Frank, Jacqueline Jaus and Sharona Sargizi-Sarlani).

Funding Open Access funding enabled and organized by Projekt DEAL. 
Open Access This article is licensed under a Creative Commons Attribution 4.0 International License, which permits use, sharing, adaptation, distribution and reproduction in any medium or format, as long as you give appropriate credit to the original author(s) and the source, provide a link to the Creative Commons licence, and indicate if changes were made. The images or other third party material in this article are included in the article's Creative Commons licence, unless indicated otherwise in a credit line to the material. If material is not included in the article's Creative Commons licence and your intended use is not permitted by statutory regulation or exceeds the permitted use, you will need to obtain permission directly from the copyright holder. To view a copy of this licence, visit http://creativecommons.org/licen ses/by/4.0/.

\section{References}

Araújo, S., Reis, A., Petersson, K. M., \& Faísca, L. (2015). Rapid automatized naming and reading performance: A meta-analysis. Journal of Educational Psychology, 107(3), 868. https://doi.org/10. $1037 / \mathrm{edu} 0000006$

Blachman, B. A. (2000). Phonological awareness. In M. L. Kamil, P. B. Mosenthal, P. D. Pearson, \& R. Barr (Eds.), Handbook of Reading Research. (Vol. 3, pp. 483-502). Lawrence Erlbaum Associates Publishers.

Boltzmann, M., Mohammadi, B., Samii, A., Münte, T. F., \& Rüsseler, J. (2017). Structural changes in functionally illiterate adults after intensive training. Neuroscience, 344, 229-242. https://doi.org/10. 1016/j.neuroscience.2016.12.049

Boltzmann, M., \& Rüsseler, J. (2013). Training-related changes in early visual processing of functionally illiterate adults: Evidence from event-related brain potentials. BMC Neuroscience, 14(1), 154. https://doi.org/10.1186/1471-2202-14-154

Bowey, J. A. (2005). Predicting individual differences in learning to read. In M. J. Snowling \& C. Hulme (Eds.), The Science of Reading: A Handbook. (pp. 155-172). Blackwell Publishing. https://doi.org/ 10.1002/9780470757642.ch9.

Braze, D., Katz, L., Magnuson, J. S., Mencl, W. E., Tabor, W., Van Dyke, J. A., ... \& Shankweiler, D. P. (2016). Vocabulary does not complicate the simple view of reading. Reading and Writing, 29(3), 435-451. https://doi.org/10.1007/s11145-015-9608-6

Catts, H. W., Adlof, S. M., \& Weismer, S. E. (2006). Language deficits in poor comprehenders: A case for the simple view of reading. Journal of Speech, Language, and Hearing Research, 49(1), 278293. https://doi.org/10.1044/1092-4388(2006/023)

Ehri, L. C. (2005). Learning to read words: Theory, findings, and issues. Scientific Studies of Reading, 9(2), 167-188. https://doi.org/10.1207/s1532799xssr0902_4.

Egloff, B., Grosche, M., Hubertus, P., \& Rüsseler, J. (2011). Funktionaler Analphabetismus im Erwachsenenalter: eine Definition [Functional illiteracy in adulthood: a definition]. In Projektträger im DLR (Hrsg.), Zielgruppen in Alphabetisierung und Grundbildung Erwachsener: Bestimmung, Verortung, Ansprache [Target Groups in Literacy and Basic Adult Education: Determination, Contextualization, Addressing] (pp. 11-31). Bielefeld: WBV. https://doi.org/10.3278/6004139w

Eme, E. (2011). Cognitive and psycholinguistic skills of adults who are functionally illiterate: Current state of research and implications for adult education. Applied Cognitive Psychology, 25(5), 753762. https://doi.org/10.1002/acp.1746

Eme, E., Lambert, E., \& Alamargot, D. (2014). Word reading and word spelling in French adult literacy students: The relationship with oral language skills. Journal of Research in Reading, 37(3), 268296. https://doi.org/10.1111/J.1467-9817.2011.01508.X

Goswami, U., Ziegler, J. C., \& Richardson, U. (2005). The effects of spelling consistency on phonological awareness: A comparison of English and German. Journal of Experimental Child Psychology, 92(4), 345-365. https://doi.org/10.1016/j.jecp.2005.06.002

Gottesman, R. L., Bennett, R. E., Nathan, R. G., \& Kelly, M. S. (1996). Inner-city adults with severe reading difficulties: A closer look. Journal of Learning Disabilities, 29(6), 589-597. https://doi.org/ 10.1177/002221949602900603

Greenberg, D., Ehri, L. C., \& Perin, D. (1997). Are word-reading processes the same or different in adult literacy students and third-fifth graders matched for reading level? Journal of Educational Psychology, 89(2), 262. https://doi.org/10.1037/0022-0663.89.2.262 
Greenberg, D., Ehri, L. C., \& Perin, D. (2002). Do adult literacy students make the same word-reading and spelling errors as children matched for word-reading age? Scientific Studies of Reading, 6(3), 221-243. https://doi.org/10.1207/S1532799XSSR0603_2

Greenberg, D., Wise, J. C., Morris, R., Fredrick, L. D., Rodrigo, V., Nanda, A. O., \& Pae, H. K. (2011). A randomized control study of instructional approaches for struggling adult readers. Journal of Research on Educational Effectiveness, 4(2), 101-117. https://doi.org/10.1080/19345747.2011. 555288

Grosche, M. (2013). Die Interaktionstheorie des funktionalen Analphabetismus [The interaction theory of functional illiteracy]. Vierteljahresschrift für Heilpädagogik und ihre Nachbargebiete [Quarterly Journal for Special Education and its Neighboring Areas], 82(2), 102-113. https://doi.org/10.2378/ vhn2013.art06d

Grosche, M., \& Grünke, M. (2011). Beeintrachtigungen in der phonologischen Informationsverarbeitung bei funktionalen Analphabeten [Impairments in phonological information processing in functional illiterates]. Zeitschrift für Pädagogische Psychologie [Journal of Educational Psychology], 25(4), 277-291. https://doi.org/10.1024/1010-0652/a000051

Grotlüschen, A., \& Buddeberg, K. (2020). LEO 2018. Leben mit geringer Literalität [Living with low literacy]. WBV.

Kreuzpointner, L., Lukesch, H., \& Horn, W. (2013). LPS-2: Leistungsprüfsystem 2. [LPS-2 Performance Test System 2.]. Hogrefe.

Kutner, M., Greenberg, E., Jin, Y., Boyle, B., Hsu, Y. C., \& Dunleavy, E. (2007). Literacy in everyday life: Results from the 2003 National Assessment of Adult Literacy (NCES 2007-490). National Center for Education Statistics.

Landerl, K., Wimmer, H., \& Frith, U. (1997). The impact of orthographic consistency on dyslexia: A German-English comparison. Cognition, 63(3), 315-334. https://doi.org/10.1016/s0010-0277(97) 00005-X

Lenhard, W., \& Schneider, W. (2006). ELFE 1-6: Ein Leseverständnistest für Erst- bis Sechstklässler [ELFE 1-6: A reading comprehension test for first to sixth graders]. Göttingen: Hogrefe.

Lyon, G. R., Shaywitz, S. E., \& Shaywitz, B. A. (2003). A definition of dyslexia. Annals of Dyslexia, 53(1), 1-14. https://doi.org/10.1007/s11881-003-0001-9

Mellard, D. F., \& Fall, E. (2012). Component model of reading comprehension for adult education participants. Learning Disability Quarterly, 35(1), 10-23. https://doi.org/10.1177/0731948711429197

Mellard, D. F., Fall, E., \& Woods, K. L. (2010). A path analysis of reading comprehension for adults with low literacy. Journal of Learning Disabilities, 43(2), 154-165. https://doi.org/10.1177/0022219409 359345

McBride-Chang, C. (1995). What is phonological awareness? Journal of Educational Psychology, 87(2), 179. https://doi.org/10.1037/0022-0663.87.2.179

Moll, K., \& Landerl, K. (2010). SLRT-II: Lese- und Rechtschreibtest [SLRT- II: Reading and spelling test]. Göttingen: Hogrefe.

Nanda, A., Greenberg, D., \& Morris, R. (2010). Modeling child-based theoretical constructs with struggling adult readers. Journal of Learning Disabilities, 43, 139-153. https://doi.org/10.1177/00222 19409359344

OECD. (2016). Skills matter: Further results from the survey of adult skills. OECD Publishing. https:// doi.org/10.1787/9789264258051-en

Petermann, F., \& Daseking, M. (2013). Manual zum Zürcher Lesetest II [Manual for the Zurich Reading Test II]. Bern:Huber.

Reiss, K., Weis, M., Klieme, E., \& Köller, O. (2019). PISA 2018. Grundbildung im internationalen Vergleich [Basic education in an international comparison]. Waxmann. https://doi.org/10.31244/97838 30991007

Seymour, P. H., Aro, M., \& Erskine, J. M. (2003). Foundation literacy acquisition in European orthographies. British Journal of Psychology, 94(2), 143-174. https://doi.org/10.1348/000712603321661 859

Share, D. L. (2008). On the Anglocentricities of current reading research and practice: the perils of overreliance on an "outlier" orthography. Psychological Bulletin, 134(4), 584. https://doi.org/10.1037/ 0033-2909.134.4.584

Snowling, M. J., \& Melby-Lervåg, M. (2016). Oral language deficits in familial dyslexia: A meta-analysis and review. Psychological Bulletin, 142(5), 498. https://doi.org/10.1037/bul0000037

Stock, C., Marx, P., \& Schneider, W. (2003). Basiskompetenzen für Lese-Rechtschreibleistungen-Ein Test zur Erfassung der phonologischen Bewusstheit vom ersten bis zum vierten Grundschuljahr [Basic 
skills for reading and writing competencies-A test measuring phonological awareness from the first to the fourth grade]. Göttingen:Hogrefe.

Thompkins, A. C., \& Binder, K. S. (2003). A comparison of the factors affecting reading performance of functionally illiterate adults and children matched by reading level. Reading Research Quarterly, 38(2), 236-258. https://doi.org/10.1598/RRQ.38.2.4

Tighe, E. L., \& Schatschneider, C. (2016). Examining the relationships of component reading skills to reading comprehension in struggling adult readers: A meta-analysis. Journal of Learning Disabilities, 49(4), 395-409. https://doi.org/10.1177/0022219414555415

Vágvölgyi, R. (2018). Linguistic, Numerical and Cognitive Foundations of Functional Illiteracy [Unpublished doctoral dissertation]. University of Tübingen.

Vágvölgyi, R., Coldea, A., Dresler, T., Schrader, J., \& Nuerk, H.-C. (2016). A review about functional illiteracy: Definition, cognitive, linguistic, and numerical aspects. Frontiers in Psychology, 7, 1617. https://doi.org/10.3389/fpsyg.2016.01617

van den Bos, K. P., Zijlstra, B. J. H., \& lutje Spelberg, H. C. (2002). Life-span data on continuous-naming speeds of numbers, letters, colors, and pictured objects, and word-reading speed. Scientific Studies of Reading, 6(1), 25-49. https://doi.org/10.1207/S1532799XSSR0601_02

Wimmer, H. (1993). Characteristics of developmental dyslexia in a regular writing system. Applied Psycholinguistics, 14(1), 1-33. https://doi.org/10.1017/S0142716400010122

Winn, B. D., Skinner, C. H., Oliver, R., Hale, A. D., \& Ziegler, M. (2006). The effects of listening while reading and repeated reading on the reading fluency of adult learners. Journal of Adolescent \& Adult Literacy, 50, 196-205. https://doi.org/10.1598/JAAL.50.3.4

Wolf, M., \& Bowers, P. G. (1999). The double-deficit hypothesis for the developmental dyslexia. Journal of Educational Psychology, 91(3), 415-438. https://doi.org/10.1037/0022-0663.91.3.415.

Ziegler, J. C., Bertrand, D., Tóth, D., Csépe, V., Reis, A., Faísca, L., ... \& Blomert, L. (2010). Orthographic depth and its impact on universal predictors of reading: A cross-language investigation. Psychological Science, 21(4), 551-559. https://doi.org/10.1177/0956797610363406

Publisher's Note Springer Nature remains neutral with regard to jurisdictional claims in published maps and institutional affiliations.

\title{
Authors and Affiliations
}

\section{Irit Bar-Kochva ${ }^{1,2}$ (D) Réka Vágvölgyi ${ }^{3,4}$ (D) Thomas Dresler ${ }^{4,5}$ (D) Benjamin Nagengast ${ }^{4,6}$ (D) Hannes Schröter ${ }^{1}$. Josef Schrader ${ }^{1,4}$. Hans-Christoph Nuerk ${ }^{4,7,8}$ (i)}

\author{
Réka Vágvölgyi \\ reka.vagvoelgyi@sowi.uni-kl.de \\ Thomas Dresler \\ thomas.dresler@uni-tuebingen.de \\ Benjamin Nagengast \\ benjamin.nagengast@uni-tuebingen.de \\ Hannes Schröter \\ schroeter@die-bonn.de \\ Josef Schrader \\ schrader@die-bonn.de \\ Hans-Christoph Nuerk \\ hc.nuerk@uni-tuebingen.de
}

1 German Institute for Adult Education - Leibniz Centre for Lifelong Learning (DIE), Bonn, Germany

2 Faculty of Human Sciences, Department of Educational and Social Science, University of Cologne, Cologne, Germany 
3 Center for Cognitive Science, Department for Cognitive and Developmental Psychology, University of Kaiserslautern, Kaiserslautern, Germany

4 LEAD Graduate School \& Research Network, University of Tübingen, Tübingen, Germany

5 Department of Psychiatry and Psychotherapy, University of Tübingen, Tübingen, Germany

6 Hector Research Institute of Education Sciences and Psychology, University of Tübingen, Tübingen, Germany

7 Department of Psychology, University of Tübingen, Tübingen, Germany

8 Leibniz-Institut für Wissensmedien, Tübingen, Germany 